\title{
Failure to Detect Viral RNA in Follicular Fluid Aspirates from a SARS-CoV-2-Positive Woman
}

\author{
Cem Demirel $^{1} \cdot$ Firat Tulek $^{1} \cdot$ Hale Goksever Celik ${ }^{2}$ (D) $\cdot$ Ersan Donmez $^{3} \cdot$ Gulsum Tuysuz $^{3} \cdot$ Bilgi Gökcan $^{1}$
}

Received: 28 December 2020 / Accepted: 14 February 2021 / Published online: 22 February 2021

(C) Society for Reproductive Investigation 2021

\begin{abstract}
Although there is no known difference between the clinical manifestations of SARS-CoV-2 in pregnant and non-pregnant women based on the studies published until now, in vitro fertilization (IVF) treatments were suspended during the pandemic due to uncertainties with the suggestions of associated societies. However, we do not have enough data on the exact effects of SARS-CoV-2 on fertility and pregnancy and whether there are damaging effects on IVF outcome. There is no available evidence about the transmission of SARS-CoV-2 by either sexual way or through intrauterine insemination (IUI) or IVF. Up until now, there is no report to document the presence or absence of viral RNA in follicular fluid of SARS-CoV-2-positive women. In this paper, we present a case of oocyte retrieval from a SARS-CoV-2-positive woman and the search for viral RNA by polymerase chain reaction (PCR) in the follicular fluid aspirates.
\end{abstract}

Keywords SARS-CoV-2 $\cdot$ Infertility $\cdot$ In vitro fertilization $\cdot$ Oocyte retrieval $\cdot$ Follicular fluid

\section{Introduction}

Right after the full blown start of the SARS-CoV-2 pandemic, professional societies published declarations and statements suggesting the temporary suspension of all assisted reproduction technologies (ART) services. As the outbreak started to wane, then guidelines for the safe resumption of infertility treatments have been put forward. As time went by, second waves of the pandemic started to sweep the world amid the emergence of vaccination programs. It is likely that the infection is going to prevail for an unpredictable period of time while there is still limited data on its effects on reproductive tissues and functions.

Hale Goksever Celik

hgoksever@yahoo.com

Cem Demirel

cemdemirel@hotmail.com

Firat Tulek

firattulek@yahoo.com

Ersan Donmez

ersan.donmez@memorial.com.tr

Gulsum Tuysuz

gulsum.tuysuz@memorial.com.tr
As in vitro fertilization (IVF) procedures are kept going on, vertical transmission through gametes or hazards for health professionals through handling of infected biological material from a positive patient are major concerns. Most recently, a very recent article by Barragan et al. failed to detect viral RNA in oocytes collected from two asymptomatic SARS-CoV-2positive women [1]. In this paper, we present a case of oocyte retrieval from a SARS-CoV-2-positive woman and the search for viral RNA by polymerase chain reaction (PCR) in the follicular fluid aspirates. Up until now, there is no report to document the presence or absence of viral RNA in follicular fluid of SARS-CoV-2-positive women.

Bilgi Gökcan

bilgi.gokcan@memorial.com.tr

1 Department of Obstetrics and Gynecology, Atasehir Memorial IVF Center, Istanbul, Turkey

2 Department of Obstetrics and Gynecology, University of Health Sciences Istanbul Kanuni Sultan Suleyman Training and Research Hospital, Istanbul, Turkey

3 Department of Embryology, Atasehir Memorial IVF Center, Istanbul, Turkey 


\section{Case Report}

A 35-year-old woman who had previously undergone 4 failed intrauterine insemination (IUI) cycles contacted our clinic coming from abroad. Her physical examination and infertility work up was unraveling. She had had undergone a laparoscopic right ovarian detorsion procedure following her third IUI cycle, due to ovarian enlargement after the stimulation.

Before commencing the IVF treatment, routine symptom triage had been performed for the woman and her husband. Implementing our IVF center policy which is to screen all women for SARS-CoV-2 infection by a nasopharyngeal swab testing with PCR before the ovarian stimulation is started, we found a negative PCR test result at the start of the stimulation. The ovarian stimulation was carried out with recombinant FSH (Gonal-F; Merck Serono, Bari, Italy) 150 IU/day from the second day of the cycle and GnRH antagonist (Cetrotide; Merck, Idron France) was added from cycle day 6 onwards. In each visit for follicular monitoring, temperature checks were performed at the entrance of the IVF clinic, together with symptom questioning. All staff and patients were obliged to wear surgical masks, actually a nation-wide obligatory practice not only limited to health facilities or indoor environments. Once there were at least two follicles $\geq 18 \mathrm{~mm}$ in diameter on ultrasound, ovulation was triggered with $0.2 \mathrm{mg}$ of a GnRH agonist (decapeptyl $0.1 \mathrm{mg}$; Ferring GmbH, Kiel, Germany) together with $250 \mu \mathrm{g}$ recombinant hCG (ovitrelle; Merck Serono, Modugno, Italy). On the next day, the couple, both woman and man, started to complain of sudden onset of malaise and mild dry cough. They did not have fever and any other symptom suggestive of SARS-CoV-2 infection. Nevertheless, they had undergone SARS-CoV-2 testing with a nasopharyngeal swab for PCR that came out to be positive for both of them. Meanwhile, the patient had started to suffer from right-sided adnexal pain. On pelvic exam and color Doppler sonography, ovarian torsion was ruled out, with a normally appearing right ovary harboring preovulatory follicles and normal venous and arterial blood flows.

A discussion was carried out with the couple, on whether to cancel the oocyte pick up or not. Considering the risk of recurrence of ovarian torsion for the enlarged right ovary, we had chosen to proceed with the egg retrieval. In order to eradicate the risk of aerosolization of viral particles during the egg retrieval, local paracervical block was planned for anesthesia.

\section{Egg Retrieval and Laboratory Procedures}

Egg retrieval procedure was carried out by staff wearing appropriate personal protective equipment (PPE), namely n95 masks, eye shielding glasses, cap, shoe covers, disposable gowns, and gloves. The patient was given a surgical mask to put on during the entire procedure and advised not to use any verbal communication. All air flow within the operating theater and IVF laboratory including the workstations were switched off. The follicular aspirates were sent to an embryology lab to search for oocytes and then pooled in triplicate test tubes from each ovary to be sent for PCR analysis for SARS-CoV-2 viral RNA. Twenty retrieved cumulus oocyte complexes were then flushed several times with incubation medium, denuded with hyaluronidase and incubated for $4 \mathrm{~h}$ before insemination with ICSI. Following ICSI and incubation of inseminated oocytes in an isolated humidified incubator, 4 blastocysts were vitrified on day 5 .

PCR analyses of follicular aspirates were all found to be negative in parallel run triplicate test tubes from each ovary.

The patient did well after the egg collection and being kept under isolation for 14 days, she and her husband recovered the COVID-19 disease without any sequela. PCR tests turned to be negative at the end of the isolation period.

\section{Discussion}

There is no data on the transmission of SARS-CoV-2 to follicular fluid in women who have active COVID-19 infection. SARS-CoV-2 has been detected in secretions, like saliva, stool, urine, and the gastrointestinal tract [2]. SARS-CoV-2 has also been identified in semen in both acute stage of infection and the recovery period suggesting that semen may be contagious for the virus [2].

In contrast, other studies failed to document viral transmission in semen samples from men with active SARS-CoV-2 infection or during the convalescence period suggesting a remote possibility for viral transmission during ART treatments $[3,4]$. In a systematic review, only 1 out of 7 studies found positive SARS-CoV-2 RNA tests in seminal fluid (6 out of 143 total men) [5]. Therefore, the debate is still going on but it seems that the transmission rate of the infection through semen is negligible, if any.

It has also been proposed that oocytes and embryos may be infected by SARS-CoV-2 which has the ability to bind the receptors $A C E 2$ and $C D 147$ resulting in poor reproductive outcomes $[6,7]$.

Previously, screening of follicular fluid for SARS-CoV-2 viral RNA was reported just in one study where all follicular samples from 156 women who tested negative for SARSCoV-2 RNA 3-4 days prior to oocyte retrieval were analyzed. The aim of this study was to prove that strict patient screening protocols would avoid the presence of viral RNA in the IVF laboratory [8]. Our study is the first to investigate detection of SARS-CoV-2 RNA in the follicular fluid of the patient having active infection. In just a single case of active SARS-CoV-2 infection confirmed by nasopharyngeal swap RT-PCR, we were unable to document the transmission of the virus into the follicular fluid. This has to be confirmed with large case series and IVF labs will inevitably be performing egg 
retrievals in women with confirmed SARS-CoV-2 infection. There is a possibility that with increasing viral loads, transmission of the viral RNA into follicular fluid may be observed.

A very recent article failed to detect viral RNA of SARSCoV-2 in oocytes from women who were positive by PCR [1]. In this report, viral RNA was undetectable in all 16 oocytes tested from two asymptomatic positive women in a donation program. The oocytes had been vitrified after collection and once the women were confirmed to be positive on the day of oocyte retrieval, they were thawed and analyzed for the presence of viral RNA after whole transcriptome amplification. Due to the nature of their screening protocol, the authors were unaware of the COVID-19 status of the women at the time of egg collection; therefore, follicular fluid samples had not been checked for the presence of viral RNA. This study confirmed the expression of two genes, namely $B S G$ and CTSL in oocytes that can facilitate the entry of SARS-CoV-2 virus into the cells, thereby raising the possibility that the oocytes are able to be infected by SARS-CoV-2 virus.

As a conclusion, our small finding and all the other data gathered so far point out that the handling of oocytes, sperm, seminal fluid, or follicular fluid in IVF laboratory may not constitute a significant threat for the healthcare professionals and laboratory setup, if the patient is SARS-CoV-2 positive. Nevertheless, before more and more data are elaborated, we must still obey strict safety protocols and consider this viral disease as a potential source of infection in IVF practice. We must still try to refrain performing ART procedures in patients discovered to have acquired the infection during the ovarian stimulation phase, until much more data are gathered on the safety of ART in asymptomatic or mildly symptomatic viral shedding patients.

\section{Declarations}

Ethical Approval As this work represents a retrospective study, no ethical approval is required according to the Local Ethics Committee opinion.

Informed Consent Written informed consent was obtained from the patient who participated in this study.

Conflict of Interest The authors declare no competing interests.

\section{References}

1. Barragan M, Guillén JJ, Martin-Palomino N, et al. Undetectable viral RNA in oocytes from SARS-CoV-2 positive women. Hum Reprod. 2020;30.

2. Li D, Jin M, Bao P, Zhao W, Zhang S. Clinical characteristics and results of semen tests among men with coronavirus disease 2019 . JAMA Netw Open. 2020;3(5):e208292.

3. Holtmann N, Edimiris P, Andree M, Doehmen C, Baston-Buest D, Adams $\mathrm{O}$, et al. Assessment of SARS-CoV-2 in human semen-a cohort study. Fertil Steril. 2020;114(2):233-8.

4. Ruan Y, Hu B, Liu Z, et al. No detection of SARS-CoV-2 from urine, expressed prostatic secretions, and semen in 74 recovered COVID19 male patients: a perspective and urogenital evaluation. Andrology. 2020;4.

5. Tur-Kaspa T, Hildebrand G, Cohen D, et al. Is COVID-19 a sexually transmitted disease? A systematic review. Fertility and Sterility. 2020;114(3):e522.

6. Essahib W, Verheyen G, Tournaye H, van de Velde H. SARS-CoV2 host receptors ACE2 and CD147 (BSG) are present on human oocytes and blastocysts. J Assist Reprod Genet. 2020;37(11):265760.

7. Virant-Klun I, Strle F. Human oocytes express both ACE2 and BSG genes and corresponding proteins: is SARS-CoV-2 infection possible? Stem Cell Rev Rep. 2021;5:1-7.

8. Rajput SK, Khan SA, Goheen BB, et al. Absence of COVID-19 virus within an active IVF laboratory using strict patient screening and safety criteria. Fertility and Sterility. 2020;114(3):e530.

Publisher's Note Springer Nature remains neutral with regard to jurisdictional claims in published maps and institutional affiliations. 